\title{
Viajar con animales hoy
}

Keywords: tenencia responsable; viajar con animales en avión; tren o barco

Durante los meses de verano -y especialmente en agosto- los viajes suelen presentar un interrogante (aparte del obvio de si, en las actuales circunstancias económicas, se va a viajar!): que es cómo viajar con nuestro animal de compañía.

He estado recientemente en USA y, por primera vez, he usado los servicios de United Airlines, una compañía estadounidense que tiene un programa especial para cuidar de los animales de compañía que vuelan con ellos. El programa ("pet safe"), incluye facilidades como disponer de unas salas en distintos aeropuertos, como el de Chicago, JFK, Las Vegas, etc, para los animales que viajan en cabina con sus dueños y están en tránsito. Aparte de que el tono de la página es positivo ("Lleve a su animal favorito con Ud. en su vuelo"), es decir, que la información que está dirigida al viajero, es clara, útil y profesional, también se percibe que United Airlines se siente responsable de la seguridad de los animales de compañía que viajan con ellos y que la compañía se siente orgullosa de ofrecer unos servicios que contribuyan al bienestar del animal y a la tranquilidad de sus dueños, como contar con una Oficina de animales vivos que funciona las 24h. del día, la capacidad de rastrear las mascotas del origen al destino y muchas cosas más.

Los que acumulamos muchas horas de vuelo con animales, sabemos cómo se agradece, desde el primer instante, que te ofrezcan, además de seguridad, un trato cordial y amable que incluya al animal que viaja. No todas las compañías son iguales. Recuerdo con especial afecto a la compañía francesa Air France, que es modélica en el embarque y desembarque de los animales que vuelan en cabina, pero, además, con la característica "gentillesse" francesa, el sobrecargo, ofrece agua al animal después de haberse ocupado de los pasajeros. Son los detalles los que hacen la diferencia. Viajar con un animal, por placer o por trabajo -lo sabemos los que tenemos que hacerlo con frecuencia-, es una de tantas muestras de lo que se denomina tenencia responsable, que evita los abandonos. Se trata de incorporar a nuestra rutina los buenos hábitos de cuidado y educación de nuestras mascotas y de influir en que los hábitos sociales también cambien: que haya más tolerancia a la presencia de los animales en lugares públicos. Los animales, como la Fundación Affinity en España no se cansa de repetir, son fuente de salud. Cada vez es menos difícil encontrar alojamientos en hoteles, en los que admitan animales de compañía. Y, cada vez, el Derecho apuesta por simplificar la normativa, relativa a los viajes en compañía de animales.

En nuestra web, dedicamos desde el principio una especial atención a este tema. Pueden leer los artículos correspondientes en la sección de Preguntas + Frecuentes, en donde se hace referencia a cuestiones como:

- ¿Puedo viajar con mi animal de compañía en tren?

- Dentro de dos mes tengo que viajar a Alemania con mi gato; ¿necesito algún documento especial para salir de España con mi gato, o es suficiente con su cartilla sanitaria?

- ¿Puedo viajar en autobús o metro con animales de compañía?

- ¿ ¿Puedo viajar con mi animal de compañía en autobús (de larga distancia)?; puedo viajar con mi animal de compañía en barco/ferry?

- ¿Puedo viajar en avión con mi animal de compañía?

El Grupo de investigación ADS, que dirijo en la UAB, ha elaborado un informe, basado en una investigación rigurosa y contrastada, acerca de los hábitos de viaje con animales de compañía y acerca de 
la normativa jurídica aplicable. En un mundo globalizado como el de hoy, éste es uno de los servicios que, los que nos dedicamos hace tantos años a la investigación, tenemos la obligación moral y cívica de cumplir.

Por lo demás, existe una asociación internacional IPATA (International Pet and Animal Transportation Association), fundada en 1969, que cuenta con más de 350 miembros en más de 70 países y que agrupa a las compañías y transportistas que consideran prioritario que el transporte de animales de compañía, respete los principios del bienestar animal y que se desarrollen estrategias para mejorar los servicios de seguridad en el transporte de animales.

Por cierto, entre las compañías europeas que son miembros activos de tal influyente asociación internacional (IPATA), se cuentan sólo, a día de hoy: Lufthansa, Air France y British Airways. Sería deseable que las compañías españolas se unieran a dicha asociación y que los viajeros (principalmente los de cuatro patas!), empezaran a notarlo!. 